\title{
The results of the study of uneven seed disper- sion by the centrifugal distribution system of a pneumatic grain seeder
}

\author{
Azamat E. Bogus ${ }^{1, *}$, Elena Zubrilina ${ }^{2}$, and Lyubov Vysochkina ${ }^{3}$ \\ ${ }^{1}$ Chair "Processes and machines in agribusiness" of the faculty of mechanization of Kuban State \\ Agrarian University named after I.T.Trubilin, 350044, Krasnodar, Russia \\ 2 Don State University, Rostov-on-Don, Gagarin sqr., 1, Russian Federation \\ ${ }^{3}$ Stavropol State Agrarian University, Stavropol, Zootechnichesky st., 12, Russian Federation
}

\begin{abstract}
There were determined the parameters and operating modes of the centrifugal dispersion system of a grain pneumatic seeder, which ensured the minimum unevenness of the seed dispersion between the seed lines.
\end{abstract}

\section{Relevance of research}

Currently, pneumatic grain seeders with centralized dispersion systems are widely used, their changeable productivity in 30 percent or more with an equal working width exceeds the productivity of units with mechanical seeders. The increase in productivity is mainly due to the reduction of unproductive time costs associated with filling the hoppers with seed material, movements and technological maintenance of the machine. However, the analysis of research papers on the problem and the results of search experiments revealed a significant drawback of their work - a high unevenness of the seed dispersion between seed lines, due to the imperfection of the technological process of seed dispersion by centralized dispersion systems. The uneven seed dispersion along seed lines undoubtedly has a negative impact on the yield of grain crops and significantly reduces the efficiency of the use of seeders with dispersion systems.

Improving the quality of seed dispersion through seed lines by justifying the parameters and operating modes of the dispersion system of a pneumatic grain seeder based on modeling the movement of seeds in a centrifugal disperser is relevant. In recent years, pneumatic grain seeders have become widely used, allowing to increase the productivity of sowing units, as well as to reduce operating costs. $[2,3,9]$. The main disadvantage of existing designs of pneumatic grain seeders is the uneven seed dispersion between the seed lines, which leads to overspending of seeds [4]. Kuban State Agrarian University has proposed a design of a centrifugal seed dispenser, which reduces the unevenness of seed dispersion along the seed lines $[1,10]$.

The design scheme of the disperser requires a theoretical justification of the design and operating parameters based on the equation of motion in the disperser's chamber.

\footnotetext{
*Corresponding author: azamat089@gmail.com
} 


\section{Investigation of uneven seed dispersion by a centrifugal dis- perser}

A multi-factor experiment was implemented in accordance with the program of laboratory and production studies of the centrifugal disperser. The experiments were carried out in three-fold repetition $[5,11]$.

Experimental studies of the transverse unevenness of the dispersion by the centrifugal dispersion system of a pneumatic grain seeder were carried out according to the Bock plan B3 (Table 1).

Table 1. Results of experimental studies of the uneven dispersion of the centrifugal dispersion system

\begin{tabular}{|c|c|c|c|c|c|c|c|c|c|c|c|c|c|}
\hline \multirow{2}{*}{$\begin{array}{c}\text { № } \\
\text { experiment }\end{array}$} & \multicolumn{7}{|c|}{ Values of factors } & \multirow{2}{*}{$Y_{1}$} & $Y_{2}$ & \multirow{2}{*}{$Y_{3}$} & \multirow{2}{*}{$Y_{c p}$} \\
\hline & $x_{1}$ & $x_{2}$ & $x_{3}$ & $x_{1} X_{2}$ & $x_{1} X_{3}$ & $x_{2} x_{3}$ & $x_{1}{ }^{2}$ & $x_{2}{ }^{2}$ & $x_{3}{ }^{2}$ & & & & \\
\hline 1 & 1 & 1 & 1 & 1 & 1 & 1 & 1 & 1 & 1 & 4,92 & 5,54 & 5,47 & 5,31 \\
\hline 2 & -1 & 1 & 1 & -1 & -1 & 1 & 1 & 1 & 1 & 6,3 & 6,72 & 5,98 & 6,33 \\
\hline 3 & 1 & -1 & 1 & -1 & 1 & -1 & 1 & 1 & 1 & 4,75 & 5,38 & 5,62 & 5,25 \\
\hline 4 & -1 & -1 & 1 & 1 & -1 & -1 & 1 & 1 & 1 & 6,25 & 5,68 & 5,23 & 5,72 \\
\hline 5 & 1 & 1 & -1 & 1 & -1 & -1 & 1 & 1 & 1 & 5,9 & 5,41 & 6,47 & 5,93 \\
\hline 6 & -1 & 1 & -1 & -1 & 1 & -1 & 1 & 1 & 1 & 8,15 & 7,44 & 7,75 & 7,78 \\
\hline 7 & 1 & -1 & -1 & -1 & -1 & 1 & 1 & 1 & 1 & 5,13 & 5,97 & 5,71 & 5,6 \\
\hline 8 & -1 & -1 & -1 & 1 & 1 & 1 & 1 & 1 & 1 & 7,39 & 7,48 & 7,95 & 7,61 \\
\hline 9 & 1 & 0 & 0 & 0 & 0 & 0 & 1 & 0 & 0 & 4,84 & 5,36 & 5,22 & 5,14 \\
\hline 10 & -1 & 0 & 0 & 0 & 0 & 0 & 1 & 0 & 0 & 5,83 & 5,11 & 5,69 & 5,54 \\
\hline 11 & 0 & 1 & 0 & 0 & 0 & 0 & 0 & 1 & 0 & 6,28 & 6,72 & 6,35 & 6,45 \\
\hline 12 & 0 & -1 & 0 & 0 & 0 & 0 & 0 & 1 & 0 & 5,18 & 4,89 & 5,62 & 5,23 \\
\hline 13 & 0 & 0 & 1 & 0 & 0 & 0 & 0 & 0 & 1 & 5,74 & 5,24 & 5,05 & 5,34 \\
\hline 14 & 0 & 0 & -1 & 0 & 0 & 0 & 0 & 0 & 1 & 5,29 & 5,88 & 5,14 & 5,44 \\
\hline
\end{tabular}

We checked the variance for the reproducibility of the experiment and tested the hypothesis of uniformity of the variance according to the Cochran criterion, the calculated value of which was 0.1305 and 0.3924 with a table value for our experiment. The hypothesis of uniformity of experience was accepted based on the condition of uniformity of the variances of the experimental results $\left(G_{c a l} \leq G_{t a b l}\right.$.). The hypothesis of the normality of the dispersion was tested using the Pearson agreement criterion.

The values of coefficients of the experimental model were calculated (Table 4.4). We checked the significance of coefficients according to the Student's $t$-test at $5 \%$ significance level of regression equations, and also determined their confidence intervals:

Table 2. Values of regression coefficients of the mathematical model equation

\begin{tabular}{|l|l|l|l|l|l|l|l|l|l|l|}
\hline Coefficient & $b_{0}$ & $b_{1}$ & $b_{2}$ & $b_{3}$ & $b_{12}$ & $b_{13}$ & $b_{23}$ & $b_{11}$ & $b_{22}$ & $b_{33}$ \\
\hline Calculated & 4,92 & $-0,57$ & 0,23 & $-0,44$ & $-0,04$ & 0,29 & 0,02 & 0,3 & 0,8 & 0,35 \\
\hline Accepted & 4,92 & $-0,57$ & 0,23 & $-0,44$ & 0 & 0,29 & 0 & 0,3 & 0,8 & 0,35 \\
\hline$t_{005}^{\text {pacu }}$ & 50,25 & 5,87 & 2,44 & 4,50 & 0,49 & 3,02 & 0,21 & 3,06 & 8,172 & 3,57 \\
\hline$t_{005}^{\text {maбn }}$ & 2,04 & 2,04 & 2,04 & 2,04 & 2,04 & 2,04 & 2,04 & 2,04 & 2,04 & 2,04 \\
\hline
\end{tabular}

The calculated factors, the criterion of which $t_{005}^{\text {pacu }}$ is greater than the tabular one $t_{005}^{\text {maбn }}$, are considered significant. Factors $b_{12}, b_{23}$ are insignificant.

Excluding factors $b_{12}, b_{23}$, we obtained a regression equation describing the dependence of parameters and operating modes of the dispersion system of a pneumatic grain seeder. After determining and substituting the coefficients of the regression equation in a polyno- 
mial of the second degree, the regression equation was obtained in encoded form:

Equation of the mathematical model of the uneven seed distribution between seed lines in encoded form:

$$
Y=4,92-0,57 X_{1}+0,239 X_{2}-0,44 X_{3}+0,296 X_{1} X_{3}+0,3 X_{1}^{2}+0,8 X_{2}^{2}+0,35 X_{3}^{2} .
$$

To check the adequacy of the model, the variance of the adequacy was determined and the value of the F-criterion was calculated: $S_{a d}^{2}=0,3349 ; F_{\text {pacu }}=2,3299$.

The calculated value of the $F$-criterion at $5 \%$ significance level and with our number of degrees of freedom is 3.7. We can accept the hypothesis about the adequacy of the model based on the condition $F_{c a l} \leq F_{t a b l}$. A mathematical model with 95\% accuracy describes the nature of the influence of factors on the response.

The influence of factors on the optimization parameter can be estimated using the diagram (Figure 1). The greatest influence on the coefficient of variation is exerted by the radius of the disperser and the speed of rotation of the fan impeller, which indirectly confirms the results of theoretical studies.

\section{Influence of factors on optimization rate}

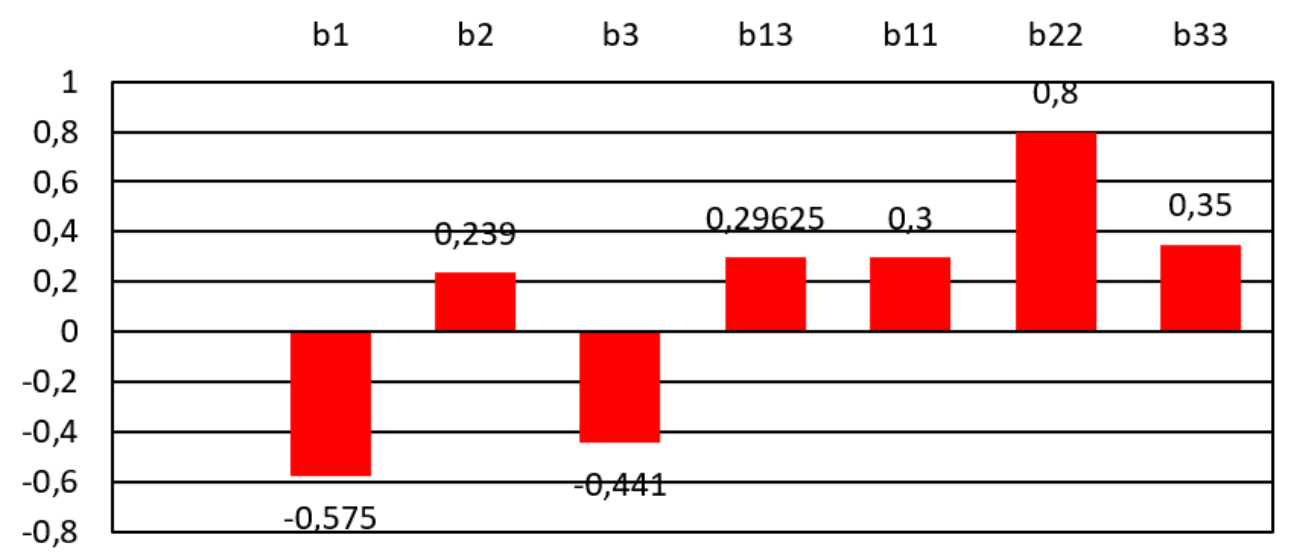

Fig. 1. Influence of factors on optimization rate

The regression equation in canonical form is the following:

$$
Y-Y_{s}=B_{1} X_{1}^{2}+B_{2} X_{2}^{2}+B_{3} X_{3}^{2}
$$

Optimal values of factors $X_{1}=0,818 ; X_{2}=-0,149 ; X_{3}=0,284$.

The resulting model (2) is three-dimensional. We can only analyze two-dimensional models. A two-dimensional model is obtained by differentiating the model (2) in partial derivatives. Therefore, we apply the following method for the convenience of its analysis. We will fix each of factors at its optimal value in turn. The other two will vary. Thus, when fixing one of the factors at the optimal value, we will get the range of variation of the other two factors and, based on its analysis, we will choose the intervals of variation of variable factors, at which the required degree of unevenness of the seed dispersion between the seed lines of the pneumatic grain seeder is provided. The graphical dependences of the disperser's radius, the minute seed supply, and the fan speed are shown in Figures 2-4.

In Figure 2, the fan speed $X_{3}=0,284$ is taken as a fixed factor. 

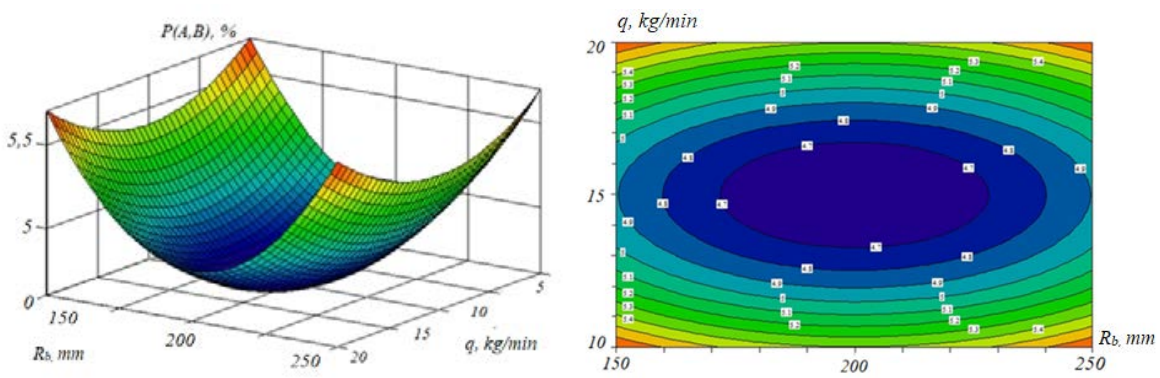

Fig. 2. Surface and cross-section of the response of dependence of the unevenness of seed disperser $P$ $(A, B)$ on the radius of the disperser $R_{b}$ and the minute seed supply $q$ at a fixed speed of the fan impeller $N_{v}$.

The transformed equation of the mathematical model in the canonical form (1) will take the form, taking into account the fixed factor $X_{3}$ :

$$
Y-Y_{s}=B_{1} X_{1}^{2}+B_{2} X_{2}^{2}
$$

In Figure 3, the minute supply of seed material is taken as a fixed factor $X_{2}=-0,149$.
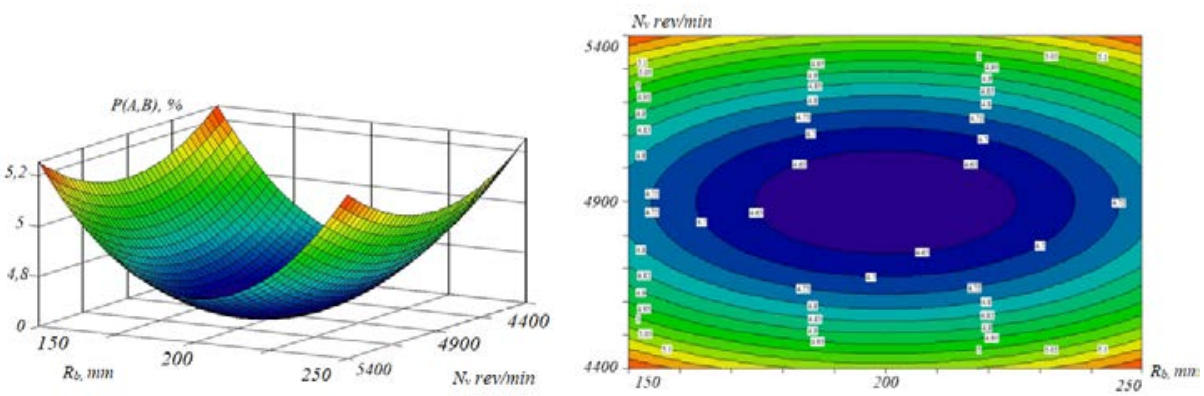

Fig. 3. Surface and cross-section of the response of dependence of the unevenness of seed disperser $P$ $(A, B)$ on the radius of the disperser $\mathrm{R}_{b}$ and the speed of rotation of the fan impeller $\mathrm{N}_{v}$ at a fixed minute seed supply $q$.

The transformed equation of the mathematical model (1) in the canonical form (2) will take the following form, taking into account the fixed factor $X_{2}$ :

$$
Y-Y_{s}=B_{1} X_{1}^{2}+B_{3} X_{3}^{2}
$$

In Figure 4, the radius of the disperser's chamber is taken as a fixed factor $X_{1}=0,818$.
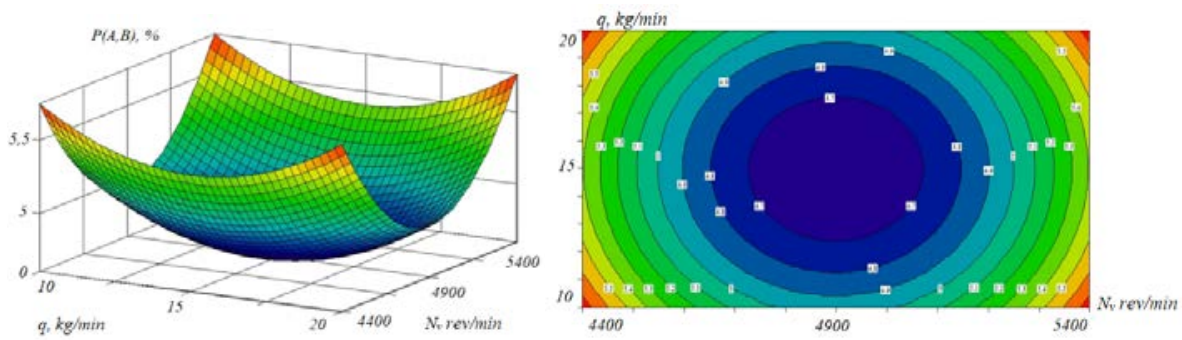

Fig. 4. Surface and cross-section of the response of dependence of the uneven seed disperser $P(A, B)$ on the minute seed supply $q$ and the speed of rotation of the fan impeller $N_{\mathrm{v}}$ at a fixed radius of the disperser's chamber $R_{b}$.

The transformed equation of the mathematical model in the canonical form (4.1) will take 
the following form, taking into account the fixed factor $X_{1}$ :

$$
Y-Y_{s}=B_{2} X_{2}^{2}+B_{3} X_{3}^{2} .
$$

The cross sections of the response surfaces shown in Figures 4.6 - 4.8 are ellipsoids, and the centers of the response cross sections are the extremum at which the minimum unevenness of the dispersion is achieved.

Coordinates of the extremum point, at which the minimum non-uniform seed dispersion between the seed lines is achieved $Y=4,6 \%: X_{1}=0,818 ; X_{2}=-0,149 ; X_{3}=0,284$.

or in natural units:

- radius of the chamber of the seed dispenser $R_{b}=241 \mathrm{~mm}$.

- minute seed supply $q=14,26 \mathrm{~kg} / \mathrm{min}$;

- frequency of rotation of the fan impeller $N_{v}=5042 \mathrm{rev} / \mathrm{min}$.

The regression equation (2) can be represented in decoded form as follows:

$$
y=68,052-0,059 x_{1}-0,912 x_{2}-0,017 x_{3}+5,92 \cdot 10^{-6} x_{1} x_{3}+3 \cdot 10^{-5} x_{1}^{2}+0,032 x_{2}^{2}+1,4 \cdot 10^{-6} x_{3}^{2} .
$$

The obtained values lie in the region of the factor space of the experiment. Therefore, the intervals and levels of variation of factors were chosen correctly.

An increase in the uneven distribution between seed lines occurs with an increase in the minute supply of seeds $q$ to the disperser, as well as with a decrease in the speed of the fan impeller $N_{v}$. It is impossible to optimize the minute seed supply $q$ as a factor, since it is determined in each specific case, depending on the established seeding rate. The negative impact of the minute feed $q$ on uneven seed dispersion can be minimized by increasing the number of dispersers on the seeder.

After analyzing the surfaces and cross-sections in Figures 2 and 3, it can be concluded that the radius of the disperser $R_{b}$ had a greater influence on the transverse unevenness of the dispersion of the seeder than the minute seed supply $q$ and the speed of the fan impeller $N_{v}$. Also, the speed of rotation of the fan impeller $N_{v}$ has a greater effect on the unevenness than the minute seed supply $q$ (Figure 4).

The obtained data allow us to form the following recommended ranges of changes in the levels of independent factors: for the radius of the seed disperser $R_{\sigma} \in[170 ; 230] \mathrm{mm}$, for minute seed supply $q \in[12 ; 18] \mathrm{kg} / \mathrm{min}$, for the speed of rotation of the fan impeller $N_{6} \in[4700 ; 5100] \mathrm{rev} / \mathrm{min}$, it corresponds to the range of speeds $u \in[13 ; 17]$.

In the course of the laboratory experiment, the probability of the seed dispersion through seed lines in the interval equal to $5 \%$ of specified seeding rate was investigated, the results of which are shown in Figure 5 [6]. The studies were carried out with a minute seed supply of 10,15 and $20 \mathrm{~kg} / \mathrm{min}$, the radius of the centrifugal disperser $R_{b}$ was $0.2 \mathrm{~m}$, and its height $h=0.8 \mathrm{~m}$, the speed of the fan impeller $N_{v}$ was assumed to be $5042 \mathrm{rev} / \mathrm{min}$, which corresponds to the air flow velocity $u$ equal to $16.42 \mathrm{~m} / \mathrm{s}$. 


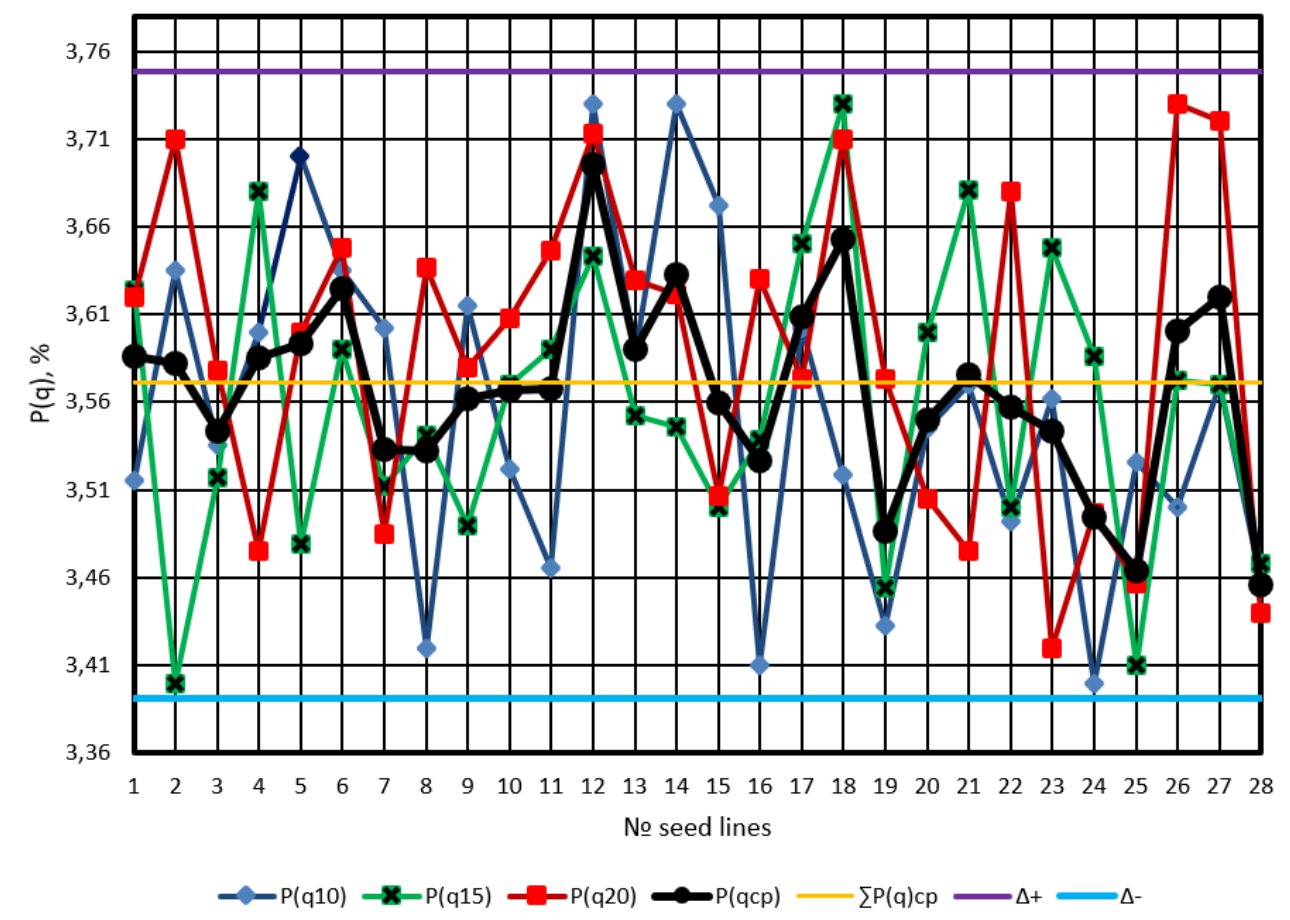

Fig. 5. Probability of seed dispersion in seed lines at different minute seed supply $q$

The results of studies of the probability of seed dispersion were processed by statistical methods using the Laplace function $[7,8]$. The probability of the random value of seed entering the one of the 28 seed lines at various minute seed supply was $94.3 \%$ at $10 \mathrm{~kg} / \mathrm{min}$, $96.83 \%$ at $15 \mathrm{~kg} / \mathrm{min}$, and $94.26 \%$ at $20 \mathrm{~kg} / \mathrm{min}$, which indicates the normal distribution of the random seed dispersion by the centrifugal dispersion system of the pneumatic grain seeder.

\section{Conclusion}

A mathematical model of uneven seed dispersion by a centrifugal dispersion system has been developed in order to confirm experimentally the parameters and operating modes of the pneumatic grain seeder. Based on the analysis, which determined that with the height of the disperser's chamber $h=0.8 \mathrm{~m}$, the radius of the disperser $R_{b}=0.241 \mathrm{~m}$ and the speed of the seed movement $u=14.26 \mathrm{~m} / \mathrm{s}$, the unevenness of the seed dispersion is $P(A, B)=4.6 \%$, which is $8.3 \%$ less than that of the serial dispersion system of the pneumatic grain seeder. The relative error in the results of experimental studies of uneven seed dispersion between the seed lines is no more than $5 \%$ of the results obtained in the course of theoretical studies.

\section{References}

1. Bogus A. Analytical study of uneven distribution of seeds by a centrifugal distributor/ A. Bogus // E3S Web of Conferences: International Conference on Modern Trends in Manufacturing Technologies and Equipment - 2020.

2. Bogus A. Investigation of the kinematics of seed movement in the centrifugal distributor of a pneumatic seeder / A. Bogus // E3S Web of Conferences: International 
Conference on Modern Trends in Manufacturing Technologies and Equipment 2020. https://doi.org/10.1051/e3sconf/202019301017.

3. Bogus A. Substantiation of the technological scheme of pneumatic grain seeder of subsurface dense sowing / Bogus A. E., Kuzmenko A. D. // E3S Web of Conferences. - 2019. - P. 00040.

4. Kastidi Yu. K. Economic efficiency of producers' provision with agricultural technology in Krasnodar Territory [Text] / Yu. K. Kastidi, D. A. Krepyshev // Proceedings of Kuban State Agrarian University - Krasnodar: Publishing house “KubSAU”, v.28, pp. 39-42(2011).

5. Klenin N.I. Agricultural machines : manual / N. I. Klenin, S. N. Kiselev, A. G. Levshin (M.: KolosS, 2008).

6. Kryuchin N.P. Development of a pneumatic seeder for sowing herbs-phytomeliorants // In thecollection: Tehnogennaja i prirodnaja bezopasnost' materialy IV Vserossijskoj nauchno-prakticheskoj konferencii [Technogenic and natural safety materials of the IV All-Russian Scientific and Practical Conference]. Saratov State Agrarian University named after N.I. Vavilova Publ. 2017. pp. 253-257.

7. N. P. Kryucliin, O. N. Serobaba, D. N. Kotov, A. N. Kryucliin Pat. №181167, Russian Federation, IPC A01C 7/00. Screw sowing apparatus. - №2018106609, declared 02/21/2018; publ. 07/05/2018 Bull. №19

8. Trubilin E. I. Experimental studies of parameters of pneumatic slot sprayer / E. I. Trubilin, S. I. Borisova, V. I. Konovalov, M. I. Chebotarev, A. D. Gumbarov // International Journal of Emerging Trends in Engineering Research. - 2020. - V. 8. № 1. P. 170-176.

9. V. I. Konovalov, S. I. Konovalov, O. V. Konovalova, E. S. Movchan, Flexible rotating harrows, Patent 173221 of the RF, MPK A01V 21/00, applicant and patent holder. Federal State Budgetary Educational Institution "Kuban State Agrarian University named after I. T. Trubilin” № 2017125814, order 18.07.2017, published 26.03.2018, Bul, v. 9, pp. 5

10. Yatskul A. I., Lemière J. P. Experimental determination of flow concentration for pneumatic conveying systems of air-seeders // INMATEH-Agricultural Engineering. 2014.- №.44(3). - pp. 1724.

11. Yu. A. Saveliev, N. P. Kryucliin, D. N. Kotov, A. N. Kryucliin. Pat No. 133677, Russian Federation, IPC A01C 7/00. Sowing apparatus. - № 2013121148/13; declared 05/07/2013; publ. 10/27/2013, Bull. №30. 